\title{
Effects of melengestrol acetate supplementation after fixed-timed artificial insemination on pregnancy rates of Bos indicus beef cows
}

\author{
W.M. Costa Junior ${ }^{\mathrm{a}}$, R.F. Cooke ${ }^{\mathrm{b}, *}$, M.H.C. Pereira ${ }^{\mathrm{a}}$, J.L.M. Vasconcelos ${ }^{\mathrm{a}, *}$ \\ a São Paulo State University (UNESP), School of Veterinary Medicine and Animal Science, Botucatu 18168-000, Brazil \\ b Texas A \& M University - Department of Animal Science, College Station, TX 77845, USA
}

\section{A R T I C L E I N F O}

\section{Keywords:}

Artificial insemination

Beef cows

Melengestrol acetate

Pregnancy rate

\begin{abstract}
A B S T R A C T
This experiment compared pregnancy rates in Bos indicus cows assigned to temporary calf weaning (TCW) or eCG administration during estrus synchronization, with or without melengestrol acetate (MGA) supplementation after artificial insemination (AI). A total of 3042 lactating, multiparous, non-pregnant Nelore cows were managed in 48 groups, and assigned to an estrus synchronization + fixed-time AI protocol ( $\mathrm{d}-11$ to 0 , with $\mathrm{AI}$ on $\mathrm{d}$ 0 ). On $d-11$, groups were randomly assigned to receive 1 of 2 gonadotropic stimulus, which were either 48-h TCW from $\mathrm{d}-2$ to AI ( $\mathrm{n}=9$ groups, 604 cows) or 300 IU i.m. injection of eCG on $\mathrm{d}-2$ ( $\mathrm{n}=39$ groups, 2438 cows). On d 1, groups were assigned to receive, in a $2 \times 3$ factorial arrangement, 1 of 3 MGA treatments: 0.5 mg of MGA/cow from d 5-18 (M5to18; $\mathrm{n}=16$ groups, 1074 cows) or from d 13-18 (M13to18; $\mathrm{n}=16$ groups, 971 cows), or no MGA supplementation (CON; $n=16$ groups, 997 cows). Estrus expression was evaluated by painting the tailhead of each cow on $\mathrm{d}-2$, and evaluating the presence of tailhead paint at AI. Body condition score (BCS; 1 -9 scale) was recorded at AI, and cows were classified as adequate $(\geq 4.5)$ or inadequate $(<4.5)$ BCS. Pregnancy rates on $\mathrm{d} 30$ and 80 were greater $(P \leq 0.05)$ in M5to18 and M13to18 compared with CON cows $(62.9 \%, 62.9 \%$, and $55.3 \%$ on $\mathrm{d} 30,58.1 \%, 59.2 \%$, and $50.5 \%$ on d 80 , respectively; SEM $=3.1)$, and similar $(P$ $\geq 0.79)$ between M5to18 and M13to18 cows. Pregnancy rates on d 30 and 80 were similar $(P \geq 0.17)$ between cows assigned to eCG and TCW (58.1\% and $62.6 \%$ on d $30,54.3 \%$ and $57.6 \%$ on d 80 , respectively; SEM $=2.7)$. The MGA supplementation $\times$ gonadotropic stimulus interaction was not significant $(P \geq 0.41)$ whereas no interactions of main treatment effects with cow BCS and estrus expression were detected $(P \geq 0.21)$ for pregnancy outcomes. Hence, supplementing $B$ indicus beef cows with MGA post-AI increased pregnancy rates compared with non-supplemented cows, and this outcome was independent of period and length of MGA supplementation, gonadotropic stimulus, cow BCS status, and estrus expression during the synchronization protocol.
\end{abstract}

\section{Introduction}

Early embryonic loss is a major reproductive challenge in cow-calf systems, and is defined as losses that occur from conception to d 27 of gestation (Humbolt, 2001). Hence, strategies to enhance early embryonic survival are warranted for optimal reproductive and overall efficiency of cow-calf operations. Progesterone (P4) is a key hormone involved in early pregnancy by regulating histotroph secretion and composition (Faulkner et al., 2013; Lonergan and Forde, 2014), modulating expression of endometrial genes associated with pregnancy establishment (Satterfield et al., 2006; Forde et al., 2009, 2011a), and influencing conceptus elongation (Lawson and Cahill, 1983; Mann et al., 2006; Clemente et al., 2009). Accordingly, circulating P4 concentrations after breeding have been positively associated with pregnancy rates in cattle (Robinson et al., 1989; Stronge et al., 2005).
Several strategies to manipulate post-breeding P4 concentrations were developed to enhance reproductive efficiency in beef females (Vasconcelos et al., 2014). As an example, our research group supplemented beef cows with melengestrol acetate (MGA; synthetic progestogen) from d 13-18 after fixed-time artificial insemination (AI), with the original intent of stimulating and synchronizing estrus resumption of cows that failed to conceive (Aono et al., 2008). Interestingly, cows supplemented with MGA had greater pregnancy rates to fixed-time AI compared with non-supplemented cows, suggesting that post-AI MGA supplementation may be an alternative to enhance pregnancy success in cattle. Nevertheless, Demetrio et al. (2007) reported that pregnancy rates in cattle are influenced by serum $\mathrm{P} 4$ concentrations on $\mathrm{d} 7$ but not on d 14 after AI. Based on these outcomes, we hypothesized that beginning MGA supplementation prior to $\mathrm{d} 7$ after fixed-time AI will further increase the MGA benefits on pregnancy success reported by

\footnotetext{
* Corresponding authors.

E-mail addresses: reinaldocooke@tamu.edu (R.F. Cooke), vasconcelos@fmvz.unesp.br (J.L.M. Vasconcelos).
} 
Aono et al. (2008).

In South America and many parts of the world, estrus synchronization + fixed-time AI protocols often include additional gonadotropic stimulus such as eCG administration or temporary calf removal (TCW; Vasconcelos et al., 2014). Although the adoption of either or both gonadotropic stimuli have resulted in similar benefits on pregnancy rates to fixed-time AI (Sá Filho et al., 2009a), Carvalho et al. (2016) reported that circulating P4 concentrations $7 \mathrm{~d}$ after fixed-time AI were less in cows assigned to TCW compared with cows receiving eCG. Hence, we also hypothesized that MGA supplementation would be of further benefit if provided to beef cows assigned to an estrus synchronization + fixed-time AI protocol including TCW compared with cCG administration.

To test these hypotheses, this experiment was designed to compare pregnancy rates in Bos indicus cows assigned to TCW or eCG administration during an estrus synchronization protocol, and receiving or not MGA supplementation during different periods after fixed-time AI.

\section{Materials and methods}

This experiment was conducted from October 2013 to March 2014 in a commercial cow-calf ranch located in Porto Estrela, Mato Grosso, Brazil. All animals utilized were cared for in accordance with the practices outlined in the Guide for the Care and Use of Agricultural Animals in Agricultural Research and Teaching (FASS, 2010). Cows were managed similarly independently of MGA supplementation or gonadotropic stimuli treatments, following the existing nutritional, reproductive, and sanitary procedures of the ranch.

\subsection{Animals and treatments}

A total of 3042 lactating, multiparous, non-pregnant Nelore cows [body condition score $(\mathbf{B C S})=4.51 \pm 0.01$ according to Wagner et al. (1988)], between 40 and 80 d postpartum, were assigned to the experiment. Hence, cows were enrolled in this experiment within the recommended voluntary waiting period for $B$. indicus-influenced cattle to optimize pregnancy rates to timed-AI (Cooke et al., 2009) and maintain a 365-d calving interval (Vasconcelos et al., 2014). Cows were managed in 48 groups, with an average of 65 cows in each group (range $=35-115$ cows/group) according to the general management scheme of the operation, and this arrangement was maintained throughout the experimental period ( $\mathrm{d}-41$ to 80 ). Groups were maintained in individual Brachiaria brizantha pastures with ad libitum access to water and a commercial mineral supplement (Nutrideal Nutrição Animal, Cuiabá, MT, Brazil).

All groups were assigned to an estrus synchronization + fixed-time AI protocol (Meneghetti et al., 2009; d -11 to 0). More specifically, cows received a $2 \mathrm{mg}$ injection (i.m.) of estradiol benzoate (Gonadiol; Zoetis, São Paulo, SP, Brazil) and an intravaginal P4 releasing device (CIDR, originally containing $1.9 \mathrm{~g}$ of P4; Zoetis) on d -11 , a $12.5 \mathrm{mg}$ injection (i.m.) of $\mathrm{PGF}_{2 \alpha}$ (Lutalyse; Zoetis) on $\mathrm{d}-4$, CIDR removal in addition to $0.6 \mathrm{mg}$ injection (i.m.) of estradiol cypionate (ECP; Zoetis) on $\mathrm{d}-2$, and fixed-time $\mathrm{AI}$ on $\mathrm{d} 0$. On $\mathrm{d}-11$, however, groups were randomly assigned to receive: 1) 48-h TCW from d -2 (immediately after CIDR removal) to $\mathrm{AI}$ ( $\mathrm{n}=9$ groups, 604 cows total), or 2) $300 \mathrm{IU}$ injection (i.m.) of eCG (Novormon, Zoetis) administered concurrently with estradiol cypionate on $\mathrm{d}-2(\mathrm{n}=39$ groups, with 2438 cows total). The commercial operation favored the use of eCG instead of TCW due to labor availability, hence the difference in number of groups assigned to each gonadotropic stimuli.

After fixed-time AI, groups were randomly assigned to receive, in a $2 \times 3$ factorial arrangement: 1) $0.5 \mathrm{mg}$ of MGA per cow from d 5-18 after fixed-time AI (M5to18; $\mathrm{n}=16$ groups, with 1074 cows total), 2) $0.5 \mathrm{mg}$ of MGA per cow from d 13-18 after fixed-time AI (M13to18; $\mathrm{n}$ $=16$ groups, with 971 cows total), or 3 ) no MGA supplementation after fixed-time AI (CON; $\mathrm{n}=16$ groups, with 997 cows total). Daily intake of the commercial mineral supplement was evaluated within each group from $\mathrm{d}-41$ to -11 of the experiment. The MGA was included in the mineral supplement to provide $2.28 \mathrm{mg}$ of MGA Premix (Zoetis) per cow daily, based on the average intake ( $d-41$ to -11$)$ of the commercial mineral supplement of each group as previously described (Sá Filho et al., 2009b; Martins et al., 2015). The MGA premix + mineral mixture was offered to M5to18 and M13to18 groups daily at $0700 \mathrm{~h}$. Cows were inseminated by 1 of 15 technicians with semen from 50 different sires. The proportion of cows inseminated by each technician, sire, and the combination of technician and sire was balanced within each treatment combination.

To facilitate cattle management and sampling procedures, groups (n $=6$ ) started the supplement evaluation and estrus synchronization + fixed-time AI protocol 2-3 d apart, totaling 8 enrollment events. Treatments assignment to groups was balanced within and across enrollment events. Hence, all groups started and completed their experimental procedures within $30 \mathrm{~d}$, but following the same experimental schedule (d -41 to 80 ).

\subsection{Evaluations}

On $\mathrm{d}-2$ of the estrus synchronization protocol, immediately after CIDR removal, the tailhead of each cow was painted (Walmur Instrumentos Veterinários, Porto Alegre, RS, Brazil). At fixed-time AI on $\mathrm{d} 0$, cows with missing or disrupted paint strip were considered to have expressed estrus activity between CIDR removal and AI (Bridges et al., 2008).

Cow BCS was evaluated at AI (Wagner et al., 1988), and cows were classified based on BCS as either adequate (BCS $\geq 4.5$ ) or inadequate (BCS < 4.5) as described by Sá Filho et al. (2010). Pregnancy status was verified by detecting a viable conceptus or fetus, respectively, on d 30 and 80 via transrectal ultrasonography (Mindray-2200VET DP; Mindray Bio-Medical Electronics Co., Shenzhen, China). Pregnancy loss was considered in cows that were pregnant on $\mathrm{d} 30$ but non-pregnant on $\mathrm{d} 80$.

\subsection{Statistical analysis}

Group was considered the experimental unit, given that MGA treatments were administered to each group. Quantitative (BCS) and binary (estrus expression and pregnancy outcomes) data were analyzed, respectively, with the MIXED and GLIMMIX procedures of SAS (SAS Inst., Inc., Cary, NC, USA) and Satterthwaite approximation to determine the denominator degrees of freedom for the tests of fixed effects. The model statement used for analysis of BCS and estrus expression contained the fixed effects of MGA supplementation (CON, M5to18, or M13to18), gonadotropic stimulus (eCG or TCW), and the resultant interaction, with group(MGA supplementation $\times$ gonadotropic stimulus) and cow(group) as random variables. The model statement used for pregnancy data contained the fixed effects of MGA supplementation (CON, M5to18, or M13to18), gonadotropic stimulus (eCG or TCW), estrus expression from $\mathrm{d}-2$ to 0 , BCS (adequate or inadequate), and all resultant interactions. Pregnancy data were analyzed using group(MGA supplementation $\times$ gonadotropic stimulus), cow(group), sire, and AI technician as random variables. Results are reported as least square means and separated using least square differences. Significance was set at $P \leq 0.05$, and tendencies were determined if $P>0.05$ and $\leq 0.10$.

\section{Results}

The MGA supplementation $\times$ gonadotropic stimulus interaction was not significant for any of the variables reported herein $(P \geq 0.41)$; hence, results are reported according to main treatment effects.

Cow BCS at fixed-time AI was similar $(P \geq 0.56)$ between eCG and TCW cows, as well as CON, M5to18, and M13to18 cows (Table 1). 
Table 1

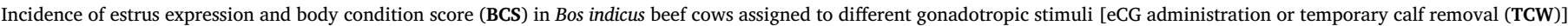
and receiving or not melengestrol acetate (MGA) supplementation after fixed-time artificial insemination (AI).

\begin{tabular}{|c|c|c|c|c|c|c|c|c|c|}
\hline \multirow[b]{2}{*}{ Item } & \multicolumn{4}{|c|}{ Gonadotropic stimulus ${ }^{a}$} & \multicolumn{5}{|c|}{ MGA supplementation ${ }^{\mathrm{b}}$} \\
\hline & TCW & eCG & SEM & $\boldsymbol{P}=$ & CON & M5to18 & M13to18 & SEM & $P=$ \\
\hline $\mathrm{BCS}^{\mathrm{c}}$ & 4.17 & 4.28 & 0.13 & 0.56 & 4.26 & 4.21 & 4.22 & 0.17 & 0.97 \\
\hline Estrus expression, ${ }^{\mathrm{d}} \%$ & 59.2 & 76.9 & 4.1 & $<0.01$ & 73.8 & 64.0 & 66.3 & 5.3 & 0.41 \\
\hline
\end{tabular}

${ }^{\text {a }}$ Cows were assigned to the same estrus synchronization + time-AI protocol (Meneghetti et al., 2009; $\mathrm{d}-11$ to 0 ). On $\mathrm{d}-11$, cows were assigned to receive 48 -h TCW from $\mathrm{d}-2 \mathrm{until}$

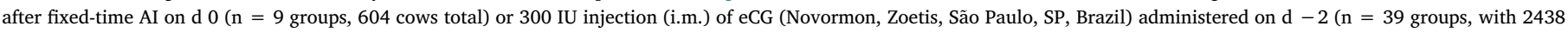
cows total).

${ }^{\mathrm{b}}$ After fixed-time AI, cows were randomly assigned to receive: 1) $0.5 \mathrm{mg}$ of MGA per cow from d 5-18 after fixed-time AI (MGA5to18; $\mathrm{n}=16$ groups, with 1074 cows total), 2) 0.5 mg

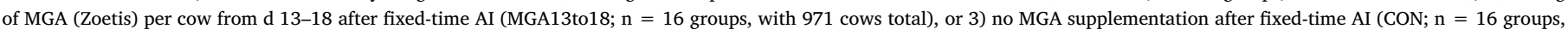
with 997 cows total).

c Evaluated at fixed-time AI, according to Wagner et al. (1988).

${ }^{\mathrm{d}}$ According to tailhead painting (Bastão de cera Walmur, Walmur Instrumentos Veterinários, Porto Alegre, RS, Brazil) based on Bridges et al. (2008).

Estrus expression was also similar $(P=0.41)$ among cows assigned to CON, M5to18, and M13to18 (Table 1). However, incidence of estrus was greater $(P<0.01)$ in cows assigned to eCG compared with cows assigned to TCW (Table 1 ).

Pregnancy rates on d 30 and 80 were greater $(P \leq 0.05)$ in M5to18 and M13to18 compared with CON cows, and similar $(P \geq 0.79)$ between M5to18 and M13to18 cows (Table 2). Pregnancy rates on d 30 and 80 were similar $(P \geq 0.17)$ among cows assigned to eCG and TCW (Table 2). No main treatment effects were detected $(P \geq 0.29)$ for pregnancy loss from d 30-80 (Table 2). No interactions of main treatment effects with cow BCS and estrus expression were detected $(P \geq$ 0.21 ) for pregnancy outcomes.

Across main treatment effects, cows classified with BCS adequate had greater $(P \leq 0.04)$ pregnancy rates on $\mathrm{d} 30$ and 80 and reduced pregnancy loss from d 30-80 compared with cows with inadequate BCS ( 60.4 vs. $56.7 \%$, SEM $=2.1 ; 57.0$ vs. $51.4 \%$, $\mathrm{SEM}=2.1 ; 5.3$ vs. $9.3 \%$, $\mathrm{SEM}=0.9$, respectively). Cows that expressed estrus also had greater $(P<0.01)$ pregnancy rates on $\mathrm{d} 30$ and 80 , but similar $(P=0.51)$ pregnancy loss from $d$ 30-80 compared with cows that did not express estrus ( 63.6 vs. $51.5 \%, \mathrm{SEM}=1.9 ; 58.8$ vs. $47.9 \%$, $\mathrm{SEM}=2.1 ; 8.2$ vs. $7.2 \%$, SEM $=1.9$, respectively).

\section{Discussion}

The main goal of this experiment was to evaluate the effects of postAI MGA supplementation on pregnancy rates in $B$. indicus beef cows, expanding previous work from our research group (Aono et al., 2008). The eCG and TCW treatments were included herein to evaluate MGA supplementation in cows receiving one of these gonadotropic stimuli, given that cows administered eCG had greater circulating P4 concentrations $7 \mathrm{~d}$ after AI compared with cows assigned to TCW in Carvalho et al. (2016). The lack of MGA supplementation $\times$ gonadotropic stimulus interaction on pregnancy outcomes, however, indicates that MGA supplementation similarly impacted pregnancy rates in $B$. indicus cows receiving either TCW or eCG. Although comparing gonadotropic stimuli was not the objective of this experiment, it should be noted that the greater incidence of estrus expression in eCG vs. TCW cows was not expected (Vasconcelos et al., 2014; Carvalho et al., 2016). Yet, such difference in estrus expression did not impact subsequent pregnancy rates to AI, which were similar among cows receiving eCG or TCW treatments as previously reported (Sá Filho et al., 2009a; Vasconcelos et al., 2014; Cooke et al., 2016).

A similar rationale should be applied to cow BCS and estrus expression, which may also affect post-AI circulating P4 concentrations (Santos et al., 2001; Sá Filho et al., 2010; Carvalho et al., 2016). Hence, cows were also classified based on BCS at fixed-time AI (inadequate or adequate) and estrus expression during the synchronization protocol, to determine if these parameters would interact with main treatment effects on pregnancy outcomes. The lack of statistical interactions among these parameters indicate that MGA effects on pregnancy rates in $B$. indicus cows are independent of estrus expression during synchronization or BCS at the time of AI. Nonetheless, cow BCS and estrus expression influenced pregnancy rates in the present experiment as previously reported by others (Cooke et al., 2008; Cooke et al., 2009; Sá Filho et al., 2010; Pereira et al., 2016). Moreover, the similar BCS and incidence of cows that expressed estrus among CON, M5to18, and

Table 2

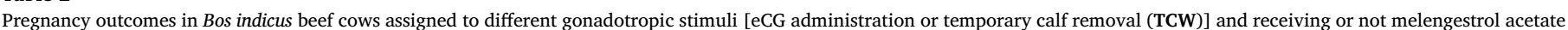
(MGA) supplementation after artificial insemination (AI).

\begin{tabular}{|c|c|c|c|c|c|c|c|c|c|}
\hline \multirow[b]{2}{*}{ Item } & \multicolumn{4}{|c|}{ Gonadotropic stimulus ${ }^{a}$} & \multicolumn{5}{|c|}{ MGA supplementation ${ }^{\mathrm{b}}$} \\
\hline & TCW & eCG & SEM & $\boldsymbol{P}=$ & CON & M5to18 & M13to18 & SEM & $\boldsymbol{P}=$ \\
\hline \multicolumn{10}{|l|}{ Pregnancy rates, ${ }^{\mathrm{c}} \%$} \\
\hline d 30 & $62.6(384 / 604)$ & $58.1(1432 / 2438)$ & 2.5 & 0.17 & $55.3^{\mathrm{a}}(554 / 997)$ & $62.9^{\mathrm{b}}(648 / 1074)$ & $62.9^{\mathrm{b}}(614 / 971)$ & 2.8 & 0.05 \\
\hline d 80 & $57.6(348 / 604)$ & $54.3(1349 / 2438)$ & 3.0 & 0.40 & $50.5^{\mathrm{a}}(513 / 997)$ & $58.1^{\mathrm{b}}(604 / 1074)$ & $59.2^{\mathrm{b}}(580 / 971)$ & 3.4 & 0.10 \\
\hline Pregnancy loss, ${ }^{\mathrm{d}} \%$ & $9.4(36 / 384)$ & $6.8(83 / 1432)$ & 1.5 & 0.29 & $9.6(41 / 554)$ & $8.3(44 / 648)$ & $6.4(34 / 614)$ & 2.0 & 0.54 \\
\hline
\end{tabular}

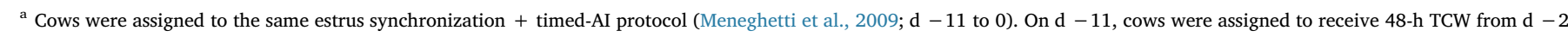

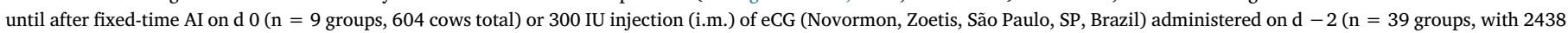
cows total).

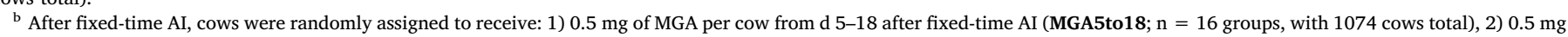

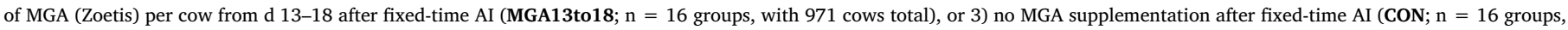
with 997 cows total).

c Pregnancy status to AI was verified on d 30 and 80 after timed-AI by detecting, respectively, a viable conceptus and fetus via transrectal ultrasonography (Mindray-2200VET DP; Mindray Bio-Medical Electronics Co., Shenzhen, China). Values within parenthesis represent number of pregnant cows divided by number of total cows assigned to fixed-time AI.

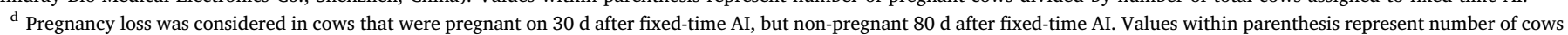
that lost AI pregnancy divided by number of diagnosed as pregnant $30 \mathrm{~d}$ after AI. 
M13to18 (Table 1) indicates that MGA supplementation effects on pregnancy outcomes were not caused by discrepancies in cow nutritional status and estrus expression among MGA treatments.

Supporting our hypothesis and previous work from our group (Aono et al., 2008), cows receiving MGA supplementation after fixed-time AI had greater pregnancy rates on d 30 and 80 compared with non-supplemented cows (Table 2). Pregnancy loss from d 30-80 did not differ among MGA treatments, indicating that MGA supplementation may have impacted early embryonic establishment but not late embryonic loss (Humbolt, 2001). Accordingly, P4 is critical for early pregnancy recognition and maintenance, including modulation of endometrial gene expression favoring embryo implantation (Mann et al., 2006; Forde et al., 2009) such as downregulation of uterine P4 receptors (Bazer et al., 2010; Okumu et al., 2010). If circulating P4 concentrations are inadequate, the ability of the uterus to support conceptus implantation and elongation is impaired (Bridges et al., 2013). Hence, supplementing MGA during the period of maternal recognition of pregnancy and preceding implantation increased pregnancy rates to fixed-time AI herein (Table 2) and in Aono et al. (2008).

Contrary to our hypothesis, however, pregnancy outcomes were similar among M5to18 and M13to18 cows. Previous research documented that embryo development to the hatched blastocyst stage (d 11 after conception) depends on the histotroph as a source of nutrients, enzymes, and growth factors (Burns et al., 2014; Forde et al., 2014). In turn, histotroph secretion and composition are directly regulated by circulating P4 (Dorniak et al., 2013; Brooks et al., 2014; Lonergan and Forde, 2014). Accordingly, circulating P4 concentrations during the initial $7 \mathrm{~d}$ of gestation were positively associated with conceptus size on d 14 of gestation (Forde et al., 2009) and with pregnancy success in dairy cows (Demetrio et al., 2007). Hence, supplementing MGA during the pre-blastocyst stage was expected to benefit embryo development and pregnancy establishment by enhancing histotroph secretion and quality, as reported by Satterfield et al. (2010) in ewes supplemented with exogenous P4 during the initial $9 \mathrm{~d}$ of gestation. However, results from this experiment do not support this rationale, given that beginning MGA supplementation on $\mathrm{d} 5$ post-AI failed to enhance pregnancy success beyond the benefits of MGA supplementation from d 13-18 post-AI.

Earlier work with beef and dairy cattle corroborate our findings that P4 supplementation after breeding increases pregnancy rates (Robinson et al., 1989; Stronge et al., 2005; Parr et al., 2012). Contrariwise, others failed to report similar outcomes (Mann and Lamming, 1999; Lamb et al., 2010; Wiltbank et al., 2012). In fact, a quadratic relationship among circulating P4 concentrations post-breeding and embryo survival have been reported (McNeil et al., 2006; Diskin et al., 2006). Parr et al. (2012) suggested that circulating P4 concentrations should be between 2.5 and $5.2 \mathrm{ng} / \mathrm{mL}$ from d 4-7 of gestation to maximize pregnancy likelihood in dairy cows. Hence, it appears that the different findings in the literature utilizing either natural or synthetic progestogen supplementation after AI may be associated with basal circulating P4 concentration in the studied population. One can speculate that supplementing P4 post-breeding enhances uterine processes required for a successful pregnancy when circulating P4 is limited, but may be unnecessary and detrimental to pregnancy rates when circulating P4 concentrations are adequate.

This latter rationale may help explaining the similar pregnancy rates between M5to18 and M13to18 cows, and the lack of interaction among MGA treatments with gonadotropic stimulus, BCS status, and estrus expression reported herein. Perhaps basal circulating P4 concentration was insufficient to support uterine processes required for pregnancy recognition and embryo implantation in the cows utilized herein (Mann et al., 2006; Forde et al., 2009; Bridges et al., 2013), independently of whether cows received eCG or TCW, exhibited adequate or inadequate BCS at fixed-time AI, or expressed estrus or not during the synchronization protocol. Conversely, our findings suggest that circulating P4 concentration were likely adequate to support the uterine processes associated with pre-blastocyst development (Dorniak et al., 2013; Brooks et al., 2014; Lonergan and Forde, 2014), and cows only benefited from supplemental P4 beginning on d 13 of gestation. Nevertheless, circulating P4 concentrations were not evaluated herein; hence, research is required to support this rationale and to further understand and establish the benefits of post-AI MGA supplementation to $B$. indicus beef cows.

\section{Conclusions}

In this experiment, supplementing $B$ indicus beef cows with MGA post-AI increased pregnancy rates compared with non-supplemented cows. This outcome was observed when MGA was supplemented from d $5-18$ or d 13-18 of gestation, and across gonadotropic stimulus (eCG or TCW), BCS status (adequate or inadequate), and estrus expression during the synchronization protocol. Although research is still warranted to fully elucidate the physiological mechanisms underlying these outcomes, MGA supplementation post-AI appears to be a feasible strategy to increase reproductive efficiency in $B$. indicus beef cows.

\section{Conflict of interest}

Nothing to report.

\section{References}

Aono, F.H.S., Peres, R.F.G., Marcon, C.C., Claro Junior, I., Lopes, C.N., Sá Filho, O.G., Pereira, M.H., Vasconcelos, J.L.M., 2008. Effects of MGA premix associated to calf removal to synchronize heat return after TAI in suckled Nellore cows. Acta Sci. Vet. 36 (622-622).

Bazer, F.W., Spencer, T.E., Johnson, G.A., Burghardt, R.C., 2010. Uterine receptivity to implantation of blastocysts in mammals. Front. Biosci. 3, 745-767.

Bridges, G.A., Day, M.L., Geary, T.W., Cruppe, L.H., 2013. Triennial reproduction symposium: deficiencies in the uterine environment and failure to support embryonic development. J. Anim. Sci. 91, 3002-3013.

Bridges, G.A., Helser, L.A., Grum, D.E., Mussard, M.L., Gasser, C.L., Day, M.L., 2008. Decreasing the interval between GnRH and PGF $2 \alpha$ from 7 to 5 days and lengthening proestrus increases timed-AI pregnancy rates in beef cows. Theriogenology 69, $843-851$.

Brooks, K., Burns, G., Spencer, T.E., 2014. Conceptus elongation in ruminants: roles of progesterone, prostaglandin, interferon tau and cortisol. J. Anim. Sci. Biotechnol. $5,53$.

Burns, G., Brooks, K., Wildung, M., Navakanitworakul, R., Christenson, L.K., Spencer, T.E., 2014. Extracellular vesicles in luminal fluid of the ovine uterus. Plos One 9, 90913.

Carvalho, E.R., Martins, T., Lamb, G.C., Vasconcelos, J.L.M., 2016. Ovulation time in suckled beef cows is anticipated by use of low doses of progesterone and temporary calf removal on fixed timed AI protocol. Theriogenology 86, 2238-2243.

Clemente, M., de La Fuente, J., Fair, T., Al Naib, A., Gutierrez-Adan, A., Roche, J.F., Rizos, D., Lonergan, P., 2009. Progesterone and conceptus elongation in cattle: a direct effect on the embryo or an indirect effect via the endometrium? Reproduction 138, 507-517.

Cooke, R.F., Arthington, J.D., 2008. Case study: effects of the protein source added to molasses-based supplements on performance of mature Brahman-crossbred cows grazing winter range. Prof. Anim. Sci. 24, 264-268.

Cooke, R.F., Arthington, J.D., Araujo, D.B., Lamb, G.C., 2009. Effects of acclimation to human interaction on performance, temperament, physiological, and pregnancy rates of Brahman-crossbred cows. J. Anim. Sci. 87, 4125-4132.

Cooke, R.F., Peres, R.F.G., Cipriano, R.S., Guarnieri Filho, T.A., Marques, R.S., Rodrigues, M.C., Carvalho, R.S., Bohnert, D.W., Vasconcelos, J.L.M., 2016. Impacts of meloxicam prior to temporary calf weaning on physiological and reproductive responses of Bos indicus beef cows. J. Anim. Sci. 94, 406-411.

Demetrio, D.G.B., Santos, R.M., Demetrio, C.G.B., Vasconcelos, J.L.M., 2007. Factors affecting conception rates following artificial insemination or embryo transfer in lactating Holstein cows. J. Dairy Sci. 90, 5073-5082.

Diskin, M.G., Murphy, J.J., Sreenan, J.M., 2006. Embryo survival in dairy cows managed under pastoral conditions. Anim. Reprod. Sci. 96, 297-311.

Dorniak, P., Bazer, F.W., Spencer, T.E., 2013. Physiology and endocrinology symposium: biological role of interferon tau in endometrial function and conceptus elongation. J. Anim. Sci. 91, 1627-1638.

FASS, 2010. Guide for the Care and Use of Agricultural Animals in Agricultural Research and Teaching, 3rd rev. Federation of Animal Science Societies, Savoy, IL, USA.

Faulkner, S., Elia, G., O’Boyle, P., Dunn, M., Morris, D., 2013. Composition of the bovine uterine proteome is associated with stage of cycle and concentration of systemic progesterone. Proteomics 13, 3333-3353.

Forde, N., Carter, F., Fair, T., Crowe, M.A., Evans, A.C.O., Spencer, T.E., Bazer, F.W., McBride, R., Boland, M.P., O'gaora, P., Lonergan, P., 2009. Progesterone-regulated changes in endometrial gene expression contribute to advanced conceptus 
development in cattle. Biol. Reprod. 81, 784-794.

Forde, N., Carter, F., Spencer, T.E., Bazer, F.W., Sandra, O., Mansouri-Attia, N., Okumu, L.A., McGettigan, P.A., Mehta, J.P., McBride, R., O'Gaora, P., 2011a. Conceptus-induced changes in the endometrial transcriptome: how soon does the cow know she is pregnant? Biol. Reprod. 85, 144-156.

Forde, N., McGettigan, P.A., Mehta, J.P., O'Hara, L., Mamo, S., Bazer, F.W., Spencer, T.E., Lonergan, P., 2014. Proteomic analysis of uterine fluid during the pre-implantation period of pregnancy in cattle. Reproduction 147, 575-587.

Humbolt, P., 2001. Use of pregnancy specific proteins and progesterone assays to monitor pregnancy and determine the timing, frequencies and sources of embryonic mortality in ruminants. Theriogenology 56, 1417-1433.

Lamb, G.C., Dahlen, C.R., Larson, J.E., Marquezini, G., Stevenson, J.S., 2010. Control of the estrous cycle to improve fertility for fixed-time artificial insemination in beef cattle: a review. J. Anim. Sci. 88, E181-E192.

Lawson, R.A.S., Cahill, L.P., 1983. Modification of the embryo-maternal relationship in ewes by progesterone treatment early in the oestrous cycle. J. Reprod. Fertil. 67, 473-475.

Lonergan, P., Forde, N., 2014. Maternal-embryo interaction leading up to the initiation of implantation of pregnancy in cattle. Animal 8, 64-69.

Mann, G.E., Fray, M.D., Lamming, G.E., 2006. Effects of time of progesterone supplementation on embryo development and interferon-tau production in the cow. Vet. J. 171, 500-503.

Mann, G.E., Lamming, G.E., 1999. The influence of progesterone during early pregnancy in cattle. Reprod. Domest. Anim. 34, 269-274.

Martins, J.H., Santos, C.S., Silva, M.A.V., Aguiar, H.M.V.S.B., França, I.G., Pereira, H.G., Ribeiro, D.L., Chaves, R.M., Souza, J.A.T., Monteiro, B.M., Sá Filho, M.F., TorresJúnior, J.R.S., 2015. Impact of puberty status and melengestrol acetate supplementation before the breeding period on reproductive efficiency of Bos indicus beef heifers. J. Anim. Sci. 93, 2796-2805.

McNeil, R.E., Diskin, M.G., Sreenan, J.M., Morris, D.G., 2006. Associations between milk progesterone on different days and with embryo survival during the early luteal phase in dairy cows. Theriogenology 65, 1435-1441.

Meneghetti, M., Sá Filho, O.G., Peres, R.F.G., Lamb, G.C., Vasconcelos, J.L.M., 2009. Fixed-time artificial insemination with estradiol and progesterone for $B$. indicus cows I: basis for development of protocols. Theriogenology 72, 179-189.

Okumu, L.A., Forde, N., Fahey, A.G., Fitzpatrick, E., Roche, J.F., Crowe, M.A., Lonergan, P., 2010. The effect of elevated progesterone and pregnancy status on mRNA expression and localisation of progesterone and oestrogen receptors in the bovine uterus. Reproduction 140, 143-153.

Parr, M.H., Mullen, M.P., Crowe, M.A., Roche, J.F., Lonergan, P., Evans, A.C.O., Diskin, M.G., 2012. Relationship between pregnancy per artificial insemination and early luteal concentrations of progesterone and establishment of repeatability estimates for these traits in Holstein-Friesian heifers. J. Dairy Sci. 95, 2390-2396.

Pereira, M.H.C., Wiltbank, M.C., Vasconcelos, J.L.M., 2016. Expression of estrus improves fertility and decreases pregnancy losses in lactating dairy cows that receive artificial insemination or embryo transfer. J. Dairy Sci. 99, 2237-2247.

Robinson, N.A., Leslie, K.E., Walton, J.S., 1989. Effect of treatment with progesterone on pregnancy rate and plasma concentrations of progesterone in Holstein cows. J. Dairy Sci. 72, 202-207.

Sá Filho, M.F.D., Crespilho, A.M., Santos, J.E.P., Perry, G.A., Baruselli, P.S., 2010. Ovarian follicle diameter at timed insemination and estrous response influence likelihood of ovulation and pregnancy after estrous synchronization with progesterone or progestin-based protocols in suckled Bos indicus cows. Anim. Reprod. Sci. 120, 23-30.

Sá Filho, O.G., Meneghetti, M., Peres, R.F.G., Lamb, G.C., Vasconcelos, J.L.M., 2009b Fixed-time artificial insemination with estradiol and progesterone for Bos indicus cows II: strategies and factors affecting fertility. Theriogenology 72, 210-218.

Sá Filho, O.G., Patterson, D.J., Vasconcelos, J.L.M., 2009a. Development of estrous synchronization protocols using melengestrol acetate in cattle. J. Anim. Sci. 87, 1981-1990.

Santos, J.E., Thatcher, W.W., Pool, L., Overton, M.W., 2001. Effect of human chorionic gonadotropin on luteal function and reproductive performance of high-producing lactating Holstein dairy cows. J. Anim. Sci. 79, 2881-2894.

Satterfield, M.C., Bazer, F.W., Spencer, T.E., 2006. Progesterone regulation of preimplantation conceptus growth and galectin 15 (LGALS15) in the ovine uterus. Biol. Reprod. 75, 289-296.

Satterfield, M.C., Gao, H., Li, X., Wu, G., Johnson, G.A., Spencer, T.E., Bazer, F.W., 2010. Select nutrients and their associated transporters are increased in the ovine uterus following early progesterone administration. Biol. Reprod. 82, 224-231.

Stronge, A.J.H., Sreenan, J.M., Diskin, M.G., Mee, J.F., Kenny, D.A., Morris, D.G., 2005. Post-insemination milk progesterone concentration and embryo survival in dairy cows. Theriogenology 64, 1212-1224.

Vasconcelos, J.L.M., Sá Filho, O.G., Cooke, R.F., 2014. Impacts of reproductive technologies on beef production in South America. Adv. Exp. Med. Biol. 752, 161-180.

Wagner, J.J., Lusby, K.S., Oltjen, J.W., Rakestraw, J., Wettemann, R.P., Walters, L.E., 1988. Carcass composition in mature Hereford cows: Estimation and effect on daily metabolizable energy requirement during winter. J. Anim. Sci. 66, 603-612.

Wiltbank, M.C., Souza, A.H., Giordano, J.O., Nascimento, A.B., Vasconcelos, J.M., Pereira, M.H.C., Fricke, P.M., Surjus, R.S., Zinsly, F.C.S., Carvalho, P.D., Bender, R.W., 2012. Positive and negative effects of progesterone during timed AI protocols in lactating dairy cattle. Anim. Reprod. Sci. 9, 231-241. 